\title{
Ciências Sociais e saude no ciclo de pesquisas no Vale do São Francisco (1950-1960)
}

| ${ }^{1}$ Nemuel Silva Oliveira, ${ }^{2}$ Marcos Chor Maio |

Resumo: No período entre 1940 e 1960, houve ampla produção acadêmica no campo da sociologia e da antropologia dos chamados estudos de comunidade no Brasil. Na era dos grandes projetos no âmbito das Ciências Sociais na década de 1950, envolvendo pesquisas sobre relações raciais, educação e saúde, cabe destacar as pesquisas realizadas no Vale do São Francisco, sob a coordenação do sociólogo Donald Pierson. Privilegia-se, neste artigo, o tema da saúde nesses estudos como um meio para tornar inteligíveis questões relevantes à época, a saber: resistências culturais à mudança; relações entre tradição e modernidade, tensões e complementaridades entre conhecimento científico e práticas populares de cura, entre outros. O exame das pesquisas do Projeto do São Francisco permitiu identificar que a questão da saúde, atrelada aos aspectos socioeconômicos e culturais, emerge como uma chave para o conhecimento das condições de vida e da realidade social das comunidades investigadas. Os cientistas sociais buscaram descrevê-las de maneira pormenorizada e abrangente, tendo o processo de mudança cultural como principal eixo de investigação. Neste artigo apresentamos as pesquisas que compuseram o referido projeto e mostramos como os cientistas sociais abordaram o tema da saúde em seus trabalhos. Ligados pelo tema da saúde, as Ciências Sociais e o contexto do desenvolvimento dos anos 1950 encontram-se reunidos no Projeto do São Francisco, cuja investigação nos permite compreender a dinâmica da mudança social naquele período.

> Palavras-chave: Ciências Sociais; História da Saúde; Estudos de Comunidade; Vale do São Francisco.

\footnotetext{
1 Graduado em História pela Universidade Federal Fluminense; mestre e doutorando em História das Ciências e da Saúde pela Casa de Oswaldo Cruz/Fiocruz. Endereço eletrônico: nemuel@ gmail.com

2 Sociólogo, pesquisador da Casa de Oswaldo Cruz/Fiocruz; professor do Programa de Pós-graduação em História das Ciências e da Saúde da Casa de Oswaldo Cruz, PPGHCS/COC/ Fiocruz. Endereço eletrônico: maio@fiocruz.br
} 


\section{Introdução}

No período entre 1940 e 1960, houve ampla produção acadêmica no campo da sociologia e da antropologia dos chamados estudos de comunidade no Brasil. Estes estiveram associados a processos de mudança social. Na era dos grandes projetos no âmbito das Ciências Sociais na década de 1950, envolvendo pesquisas sobre relações raciais, educação, saúde, cabe destacar as pesquisas realizadas no Vale do São Francisco, sob a coordenação do sociólogo Donald Pierson. Privilegiase, neste artigo, o tema da saúde nesses estudos como um meio para tornar inteligível questôes relevantes à época, a saber: resistências culturais à mudança; as relações entre tradição e modernidade, as tensões e complementaridades entre conhecimento científico e práticas populares de cura, entre outros.

Os Estudos de Comunidade (EC) configuram recurso investigativo de comunidades em processo de mudança social, deslocando métodos de pesquisa afins à Antropologia, voltados para sociedades primitivas, para pesquisas em sociedades complexas. Tais estudos exerceram papel importante na institucionalização das Ciências Sociais no Brasil, no que concerne à adoção de novos padrões de produção socioantropológica, à formação acadêmica profissional e também à execução de projetos de pesquisa social que estiveram incluídos em programas de desenvolvimento regional. O Projeto do São Francisco foi realizado sob os auspícios da Escola de Sociologia e Política de São Paulo (ELSP), do Instituto de Antropologia Social da Smithsonian Institution e da Comissão do Vale do São Francisco (CVSF) ${ }^{1}$. O projeto representa a convergência de questôes fundamentais da década de 1950, especialmente quanto à investigação do processo de mudança social e o tema do desenvolvimento.

Desde os anos de 1920 nos Estados Unidos, os EC configuravam um método investigativo de comunidades em processo de mudança social. Os pesquisadores Robert Lynd e Helen Lynd publicaram em 1929 o estudo Middletown: a study in contemporary american culture, o primeiro estudo a deslocar os métodos de pesquisa da Antropologia para estudos sobre mudança em pequenas comunidades. Os EC se ocuparam, então, inclusive no Brasil, principalmente das comunidades rurais. Mas em que consistem os EC?

Os EC configuram modalidade de pesquisa em que determinada comunidade, social e espacialmente localizada, é objeto de investigação minuciosa e detalhada sobre a vida social local. Trata-se de um "método de observação e exploração, 
comparação e verificação", cujo "propósito é antes o de usar a comunidade como um contexto para a exploração, a descoberta ou a verificação de interconexões entre fatos e processos sociais e psicológicos” (ARENSBERG; KIMBALL, 1973, p. 171).

Mudança social, industrialização e desenvolvimento foram alguns dos mais importantes temas abordados na produção das Ciências Sociais no Brasil na década de 1950, sendo a mudança social questão fulcral em diversos EC, a exemplo dos que fizeram parte do Projeto do São Francisco. As transformações socioeconômicas que os projetos de desenvolvimento potencializavam no interior do país criaram condições para que esses temas figurassem entre os interesses de pesquisa dos cientistas sociais. Elas também abriram precedentes para que as Ciências Sociais emergissem como instrumento de interpretação e explicação da dimensão e caráter das mudanças por que passava a sociedade brasileira (VILLAS BÔAS, 2007, p. 102;108).

Os EC surgiam, assim, com o propósito prático de oferecer subsídios ao trabalho de técnicos (agrônomos, médicos, administradores) responsáveis pela implantação de projetos de desenvolvimento e mudança social (NOGUEIRA, 1955, p.98). O conhecimento produzido por meio dos EC foi, ao longo dos anos de 1950, cada vez mais entendido como necessário ao desenvolvimento de programas voltados para a transformação de determinadas realidades sociais, econômicas, sanitárias, educacionais - especialmente as que se consideravam como mais atrasadas em relação à modernidade a que se pretendia conduzir o país -, e útil para a formação e treinamento de profissionais nas técnicas de investigação das Ciências Sociais.

A convergência entre os EC e os programas de desenvolvimento regional ${ }^{2}$ se deu na realização de amplos projetos de pesquisa social, como o "Projeto Columbia University/Estado da Bahia”, em que, sob os auspícios daquela universidade e da Secretaria de Educação e Saúde da Bahia - então dirigida por Anísio Teixeira -, buscou-se subsidiar políticas de modernização do interior do estado mediante a investigação de três comunidades rurais próximas a Salvador (MAIO, 1999). O Projeto do São Francisco faz parte deste contexto de realização de amplos projetos de pesquisa social, e propunha a investigação minuciosa dos diversos aspectos que compunham a estrutura sociocultural de comunidades rurais, a fim de analisar o processo de mudança social por que passavam. Foi formulado em 1949 por Donald Pierson, então diretor da Divisão de Estudos Pós-graduados 
da ELSP e professor catedrático de Sociologia e Antropologia Social na mesma instituição (CORRÊA, 1987; OLIVEIRA, 2010).

A presença de Pierson na Escola representava um alinhamento da formação de cientistas sociais no Brasil à tradição de análise sociológica preconizada pela Universidade de Chicago, cujo interesse se voltava para os problemas sociais que o crescimento das cidades norte-americanas potencializava. No Brasil, o desenvolvimento econômico e a urbanização, crescentes nos anos 1950, marcavam a transformação de um país essencialmente agrário para um urbano e industrial, gerando também problemas sociais, que os cientistas sociais então se propuseram analisar e explicar (VILLAS BÔAS, 2007). Pierson contou com a colaboração dos seguintes cientistas sociais: Alceu Maynard Araújo, Alfonso Trujillo Ferrari, Esdras Borges Costa, Fernando Altenfelder Silva, Levy Cruz e Octavio da Costa Eduardo, seus alunos e colegas de trabalho na ELSP. Estes ficaram responsáveis pela coordenação de pesquisas em pares de localidades distribuídos por todo o Vale do Rio São Francisco, e pela elaboração de monografias $^{3}$ a partir dos dados levantados.

O exame das pesquisas do Projeto do São Francisco permitiu identificar que a questão da saúde, atrelada aos aspectos socioeconômicos e culturais, emerge como uma chave para o conhecimento das condiçóes de vida e da realidade social das comunidades investigadas. Os cientistas sociais buscaram descrevê-las de maneira pormenorizada e abrangente, tendo o processo de mudança cultural como principal eixo de investigação. Assim, revelaram que as transformações no campo da saúde, que então se processavam especialmente em função de políticas públicas de saneamento, educação e incrementos econômicos, forneciam aos investigadores dados valiosos na mensuração do caráter e dimensão das mudanças que ocorriam nas comunidades rurais.

$\mathrm{O}$ entendimento de que havia um descompasso entre o desenvolvimento da medicina ocidental e a capacidade das populações em assimilá-lo foi fundamental para que os cientistas sociais apontassem a necessidade de conhecimento da cultura local para o sucesso de intervençóes do poder público no setor da saúde. A complexidade do processo de mudança que vinha na esteira dessas intervenções acentuava o caráter auxiliar do conhecimento produzido pelos cientistas sociais, sendo incorporados aos projetos de mudança como subsídio para seu planejamento. 
Neste artigo apresentamos cada uma das pesquisas que compuseram o Projeto do São Francisco, para em seguida mostrarmos como os cientistas sociais abordaram o tema da saúde em seus trabalhos, destacando convergências e especificidades de suas perspectivas. Ligados pelo tema da saúde, as Ciências Sociais e o contexto do desenvolvimento dos anos 1950 encontram-se reunidos no Projeto do São Francisco, cuja investigação nos permite compreender a dinâmica da mudança social naquele período.

\section{A realização das pesquisas no Vale do São Francisco}

Antes de analisarmos como a temática da saúde emerge nos estudos do Projeto de Pesquisas no Vale do São Francisco, é importante conhecer os próprios estudos, a fim de contextualizar a emergência do tema da saúde no projeto e a relação com a conjuntura em que ele foi realizado. Segundo Pierson, o Projeto do São Francisco consistia num estudo detalhado do modo de vida no Vale, no qual a região era tomada de forma integrada e relacionada a outras partes do país. ${ }^{4} \mathrm{~A}$ execução do projeto foi planejada em duas etapas: uma investigação preliminar - um survey ${ }^{5}$, a ser realizado antes de aprofundar a investigação com pesquisas mais sistematizadas, que compunham a segunda etapa. A partir do material coligido é que as monografias seriam produzidas. Iniciando a apresentação das pesquisas, remetemo-nos aos trabalhos de Alceu Maynard Araújo, ${ }^{6}$ responsável pelo estudo realizado na região do Baixo São Francisco, que corresponde, no estado de Alagoas, ao trecho mais próximo da foz do rio.

Em Medicina Rústica (1959), Maynard aborda os aspectos relacionados à saúde, doenças e cura na comunidade de Piaçabuçu. Em 1961, foi publicado Populaçôes Ribeirinhas do Baixo São Francisco, em que são privilegiados apenas os aspectos ecológicos da comunidade relativos à população, como provisão alimentar, habitações, vestuário, etc. Nesse trabalho, Maynard mostra que a escolha de Piaçabuçu para o estudo estava relacionada ao fato de ela ser o ponto de convergência entre diversas localidades em função da feira semanal, onde vários produtos eram vendidos (ARAÚJO, 1961, p. 9-13).

Junto com Maynard, Alfonso Trujillo Ferrari ${ }^{7}$ foi responsável por investigar uma comunidade no Baixo São Francisco - Potengi, que ficava na órbita de influência de Piaçabuçu, cuja investigação foi um desdobramento dos estudos coordenados por Maynard, sendo inicialmente preparada para lhes servir de subsídio. ${ }^{8}$ Ferrari 
realizou o recenseamento da comunidade e elaborou formulários para conduzir as entrevistas e organizar a coleta de dados. Segundo Ferrari (1960, p. 21), a comunidade era delimitada pelo âmbito das relaçóes interpessoais e comerciais que tinham na Vila seu ponto de convergência, visto que Potengi era o centro comercial, educacional, religioso, de trabalho e de divertimento da população.

No Alto São Francisco, região que corresponde à sua nascente no estado de Minas Gerais, o responsável pela coordenação das pesquisas foi Esdras Borges Costa. P Para compor o quadro comparativo, além de Pompéu - cujo nome fictício é Cerrado, foi escolhida a Fazenda Diamante - na verdade um conjunto de fazendas que ficava nos arredores de Pompéu, a que chamaram Retiro. Essas fazendas eram mais isoladas que Cerrado, apesar de manterem ainda algum contato com a cidade. ${ }^{10} \mathrm{~A}$ investigação teve o intuito de compreender a "realidade social complexa que eles [os moradores das localidades] estão vivendo" (COSTA, 1960, p.7), referindo-se o autor ao processo de mudança social.

$\mathrm{Na}$ região do Médio São Francisco, no estado da Bahia, as pesquisas foram coordenadas por Fernando Altenfelder Silva, ${ }^{11}$ que produziu dois trabalhos: Análise Comparativa de Alguns Aspectos da Estrutura Social de duas Comunidades do Vale do São Francisco (1955) e Xique-Xique e Marrecas: duas comunidades do Médio São Francisco, (1961). Ao comparar as duas localidades, Altenfelder objetivava mostrar as mudanças nas suas estruturas sociais, que se faziam sentir por meio da análise dos aspectos culturais da população (SILVA, 1961, p.298).

Levy Cruz ${ }^{12}$ foi o coordenador da equipe responsável pela investigação na comunidade de Correntina, na região dos Gerais, área situada no estado da Bahia, na divisa com Goiás. Correntina foi identificada como a comunidade com mais forte tendência à mudança, a ser comparada com outra mais isolada. Levy Cruz chegou a percorrer tal região durante um mês, encontrando apenas alguns grupos, algumas famílias, pulverizados pelos Gerais que, em conjunto, serviram de comparação com a comunidade de Correntina (informação verbal). ${ }^{13}$

A pesquisa realizada por Octavio da Costa Eduardo ${ }^{14}$ na comunidade de Cabrobó (PE) revelou que aquela era uma cidade em crescimento, haja vista a circulação de jornais e revistas, a existência de hotéis e pensões, a presença de funcionários públicos e a distribuição de energia elétrica. Além disso, a comunidade contava ainda com serviço, embora incipiente, de limpeza pública e uma cooperativa que fornecia crédito financeiro a agricultores e comerciantes. 
Os dados levantados na pesquisa, especialmente no segundo período de investigação, ${ }^{15}$ mostram mudanças que ali haviam ocorrido desde a década de 1950, como o aumento da frequência dos alunos à escola - as crianças deixaram de ser tão necessárias ao trabalho nas lavouras, além do crescimento do uso de crédito financeiro e do desenvolvimento populacional e urbano da comunidade. ${ }^{16}$

Donald Pierson, ${ }^{17}$ no estudo O Homem no Vale do São Francisco (1972), traz uma visão de conjunto dos trabalhos dos outros pesquisadores. A obra se divide em três volumes: no primeiro, Pierson descreve os aspectos físicos da região - a bacia hidrográfica do rio São Francisco, as localidades estudadas, formação geológica, clima, vegetação, fauna e abastecimento de água. Discorre também sobre o passado do Vale, as "raízes históricas de onde brota o presente" (PIERSON, 1972, II, p.VII). No segundo volume, têm destaque os aspectos ligados aos moradores do Vale e seus meios de subsistência: características da população, hábitos alimentares, habitação, vestuário, divisão do trabalho, uso da terra, agricultura, pecuária, artesanato, etc. Nele estão também os capítulos sobre higiene e hábitos corporais, doenças e seu tratamento. Já no terceiro volume, Pierson trata dos aspectos sociais e culturais, como também do ciclo de vida dos indivíduos - etiqueta, família, parentesco e compadrio, rituais, cerimônias e crenças, comportamento político, infância, fase adulta e morte, educação formal e informal. Por último, traz algumas sugestôes para pesquisas futuras e para planejamento social. Pierson esteve no Vale em 1951, com Costa Eduardo e Levy Cruz para realizar um survey, e ainda em 1959, para incluir dados sobre mudanças que poderiam ter ocorrido durante o intervalo em que as monografias estavam sendo redigidas, com financiamento da Fundação Rockefeller e da CVSF. ${ }^{18}$

Apresentados os trabalhos do Projeto do São Francisco, cabe-nos mostrar como a saúde foi abordada nesses estudos, destacando as interpretações que os cientistas sociais fizeram a partir dos dados qualitativos resultantes de suas pesquisas, e de que maneira utilizaram esta questão como chave para compreender o processo de mudança social que investigavam.

\section{As abordagens sobre saúde nos estudos do Projeto do São Francisco}

Entre os trabalhos que compóem o Projeto do São Francisco, Medicina Rústica (1959), de Alceu Maynard, é o que faz da saúde a questão central do 
estudo. Maynard utiliza dois conceitos fundamentais para sua compreensão da configuração sociocultural da comunidade: o de "medicina rústica" e de "hiato cultural”. Segundo o autor, as práticas de cura e prevenção de doenças utilizadas pela população de Piaçabuçu são resultantes do amálgama entre medicinas populares de origem portuguesa, indígena e africana - a que chamou "medicina rústica", ${ }^{19}$ compreendendo o uso de plantas e outros produtos encontrados na natureza no preparo de remédios, rezas, benzeduras e objetos considerados mágicos, assim como o conjunto de ideias relacionadas às doenças, que gravitava entre fenômenos naturais e sobrenaturais. Já o "hiato cultural" correspondia ao descompasso entre o avanço técnico da medicina ocidental e a capacidade da população de Piaçabuçu em assimilar este avanço (ARAÚJO, 1959, p. 204).

Partindo das concepções e práticas terapêuticas da população de Piaçabuçu, em relação à oferta de serviços de saúde baseados na medicina ocidental, Maynard observou que, embora a comunidade já estivesse em contato com técnicas de profilaxia e cura da medicina científica, a população resistia a incorporá-las ao seu cotidiano. Assim, o "hiato cultural" se mantinha pela força dos elementos tradicionais na vida da população, entre eles a "medicina rústica". Como aponta Maynard, esta medicina contribui também para a

[...] manutenção da estrutura social e da configuração cultural. Há, portanto, nesta monografia uma teoria implícita na exposição dos fatos da medicina rústica e essa é justamente a do hiato cultural. Há uma conexão íntima entre o folclore e a estrutura social em apreço. Conexão esta no sentido de significado (subjetivo) e função (objetivo sociocultural). A medicina rústica, como o folclore, é parte de cultura e como tal se liga à sociedade [grifos do autor] (ARAÚJO, 1959, p.204).

Desta forma, vemos que os aspectos relacionados à saúde da comunidade foram acionados para embasar uma análise da realidade social. Eles funcionaram como indicadores de um processo - o da mudança social - que não dizia respeito apenas à medicina em si, mas estava ligado à estrutura sociocultural da comunidade. Embora a mudança cultural estivesse também na perspectiva de Maynard, ele não era um "advogado da medicina ocidental" (LIMA, 2007, p.1.175), acreditando que a "medicina rústica” e a medicina ocidental não eram mutuamente excludentes. A mudança se daria, então, mais pela diluição das práticas rústicas no corpo das atividades da medicina científica, do que pela imposição e destruição das características culturais da comunidade em relação à saúde (ibidem). 
O trabalho de Ferrari (1960), por sua vez, aborda a questão da saúde no que concerne aos hábitos de higiene e na seção dedicada explicitamente à "medicina de folk", ${ }^{20}$ ao tratar de crenças e símbolos da comunidade de Potengi. Quanto aos hábitos de higiene da população de Potengi, Trujillo mostra que as próprias atividades laborais da população favoreciam o asseio corporal. A cultura de arroz, principal atividade econômica da comunidade, era realizada em locais com muita lama. Os trabalhadores costumavam, então, banhar-se no rio ao final do dia, ou lavar ao menos os pés, pois acreditavam que as doenças entravam no corpo pelo contato descalço com o solo (FERRARI, 1960 p. 47-49).

No que concerne à "medicina de folk", Ferrari afirma que a introdução dos medicamentos no conjunto das formas de tratamento, ainda que não fossem usados por toda a população, mudaram em alguma medida não apenas o índice de mortalidade e cura dos doentes, mas a própria forma de relacionar-se com a enfermidade. A causa de determinada doença deixava de estar ligada ao universo sobrenatural, porque passava a haver um medicamento específico para combater um agente conhecido pela medicina (FERRARI, 1960, p. 299).

Em Cerrado e Retiro (1960), Esdras Borges divide a seção em que aborda a questão da saúde entre higiene, doenças e práticas de cura. Na primeira parte, o autor mostra que a observância dos hábitos de higiene variava de acordo com o contexto: era mais comum serem vistas pessoas asseadas em ocasiōes sociais, no trabalho, nos fins de semana e na cidade. Já em suas próprias casas, em horas de descanso, durante a semana e principalmente na roça, as pessoas pouco faziam em relação ao asseio pessoal (COSTA, 1960, p.44-45).

A limpeza pessoal e outros hábitos de higiene eram fonte de prestígio social em Cerrado e Retiro. Embora algumas medidas como a troca diária de roupas e o uso de vaso sanitário ficassem vedados às famílias com menor poder aquisitivo, havia na comunidade o senso do mínimo de higiene que deveria ser observado por todos. Andar de roupa suja era geralmente motivo de ridicularização. Entretanto, como observou Costa, "a preocupação com a limpeza pode vir a ser considerada como antipatia, recurso para afastar pessoas, orgulho de classe, desejo de não se 'misturar' - atitudes essas que são fortemente reprovadas em Cerrado e Retiro" (COSTA, 1960, p. 43).

No que diz respeito às doenças e seu tratamento, em comparação às outras comunidades pesquisadas, como Xique-Xique e Marrecas, os moradores de 
Cerrado e Retiro (apesar dos diferentes graus de isolamento), eram os que mais recorriam aos serviços oferecidos pelos postos de saúde e os que mais utilizavam medicamentos da medicina moderna. Ainda que esses serviços fossem considerados insuficientes pela população, era comum o traslado dos doentes até comunidades vizinhas, onde houvesse maiores recursos para o seu tratamento. Mesmo as parturientes, que nas outras comunidades estudadas ainda preferiam o atendimento de parteiras locais, buscavam as maternidades existentes em outras localidades para seus partos (COSTA, 1960, p. 46).

$\mathrm{Na}$ pesquisa de Altenfelder (1961), o tema da saúde emerge inicialmente relacionado ao abastecimento de água e à possibilidade de asseio pessoal que a proximidade do rio São Francisco e de seus afluentes proporcionava. No entanto, Altenfelder observou que, apesar do acesso à água, a população não tinha o banho como hábito de limpeza, o que tornava, inclusive, grande a incidência de piolhos (SILVA, 1961, p. 66). As ideias sobre saúde e doença da população de Xique-Xique e Marrecas transitavam entre aspectos naturais e religiosos. Por um lado, achava-se que muitas doenças eram trazidas pelo ar, sendo considerados saudáveis alguns cuidados como não sair de casa quando está ventando muito. A vontade divina, por sua vez, era vista como a principal razão do surgimento de doenças, gerando na população uma atitude conformista, dificultando o processo de tratamento das enfermidades. A resignação protelava a procura por tratamento, tanto os de procedimento popular (chás, benzeduras, etc.), quanto os da medicina ocidental (ibidem).

As informações contidas nos trabalhos até aqui apresentados estão presentes e são também completadas com o estudo de Pierson (1972), em que a saúde é abordada nos capítulos intitulados "Vestuário, Higiene e outros Hábitos Corporais" e "Doenças e seu tratamento". No primeiro, Pierson chama a atenção para a existência de serviços de higiene pública, como coleta de lixo, fiscalização de matadouros e dedetização, observados na cidade de Cerrado. Descreve ainda a precariedade dos serviços de água e esgoto - inexistentes na maioria das localidades - e dos cuidados (ou falta deles) com transporte e conservação de alimentos, asseio pessoal e outros hábitos de limpeza. (PIERSON, 1972, II, p. 129-155).

Um dos destaques no trabalho de Pierson éo papel do isolamento na manutenção das práticas tradicionais em relação à saúde. $\mathrm{O}$ sistema de abastecimento de água, 
por exemplo, era precário em algumas localidades e inexistente na maioria delas,

em especial nas mais isoladas. Muitas vezes a dificuldade de acesso à comunidade, a falta de estradas ou o fato de a comunicação com as outras localidades ser feita apenas por via fluvial, privava os moradores de usufruir de materiais e tecnologias (como aparelhos sanitários e medicamentos) que poderiam melhorar as suas condições de vida. Mesmo quando havia acesso a este tipo de melhorias, ${ }^{21}$ Pierson mostra que nem sempre a comunidade compreendia o benefício que podiam trazer, continuando a proceder conforme os hábitos tradicionais. Desta forma, os estudos sobre o Vale eram também uma maneira de entender por que razão a população de algumas localidades resistiam à introdução de elementos afins ao modo de vida dos centros urbanos modernos, a exemplo de alguns hábitos de higiene como lavar as mãos antes das refeições, ou o uso do vaso sanitário.

Ao abordar a saúde, Pierson identifica assim o conflito entre dois sistemas de pensamento: de um lado, o universo de crenças populares; de outro, um sistema considerado pelo autor mais sofisticado, no sentido de que os meios de tratamento da medicina ocidental seriam melhores e mais eficazes. Pierson observa que este conflito se estabelece entre os próprios moradores da comunidade, pois ao mesmo tempo em que alguns indivíduos preservavam e preferiam continuar utilizando os tratamentos costumeiros, outros já haviam adotado práticas de cura diferentes das tradicionais, como o uso de soro antiofídico em substituição aos serviços do “curador-de-cobras” ou de medicamentos sintéticos em substituição aos chás e benzeduras (PIERSON, 1972, II, p. 186-187).

A acomodação do conflito (utilizando os termos de análise de interação social preconizado pelo sociólogo da Universidade de Chicago, Robert Park), como indicado por Pierson, aconteceria pela substituição - embora ainda limitada dos elementos culturais tradicionais pelos urbanos:

Em todas essas localidades, embora os dois sistemas de tratamento - o tradicional e de origem folk, e o mais recente e urbano - estejam agora em contato, o progresso do último sobre o primeiro é ainda muito limitado no que interessa à maior parte da população. Ainda assim, o grau de aceitação dos novos costumes, tal como o grau de contato, varia algo de lugar a lugar, de classe a classe, de família a família e, ocasionalmente, de indivíduo a indivíduo. Em todas as localidades, a eficácia de determinado remédio é geralmente medida de acordo com experiências anteriores com o mesmo e, sobretudo, com a aparente resistência que conferia ou não à moléstia em questão ou pelo menos à diminuição ou desaparecimento dos sintomas (PIERSON, 1972, II, p. 196). 
Desta forma, identifica-se a utilização dos aspectos relacionados à saúde na análise feita por Pierson do processo de mudança cultural, assim como de outros aspectos como comportamento social, por exemplo. $\mathrm{O}$ trecho em destaque ratifica que a saúde constituiu um lugar de investigação de questôes socioculturais. Isto é pertinente não apenas a este trabalho, mas também às outras pesquisas que compõem o Projeto do Vale do São Francisco.

Sobre os meios de cura também abordados por Araújo, Ferrari, Borges Costa e Silva, como uso de chás, dietas e outras prescrições, Pierson apresenta diversas informaçôes complementares e maior detalhamento dos procedimentos. Para os chás e misturas, ele traz um quadro com diversos nomes de plantas (nome popular e científico), as localidades em que são encontradas, a parte da planta (caule, folhas, sementes ou raízes) que são usadas para fazer os remédios e a doença para qual o preparado era indicado. Além disso, descreve o preparo e as formas de ingestão/uso costumeiros, que combinam os chás, unguentos, e fortificantes com simpatias e orações, como também as benzeduras, orações e o trabalho de curandeiros e feiticeiros (PIERSON, 1972, II, p. 211-240).

A única comunidade em que feiticeiros, curandeiros e benzedores não representavam as formas de tratamento mais usadas pela população foi Correntina. Levy Cruz afirma que naquela comunidade, embora houvesse a crença de que algumas doenças, como "quebranto" só poderiam ser curadas com benzeduras, era disseminado o uso de medicamentos vendidos em farmácias. Era comum também o uso simultâneo desses medicamentos com práticas diferentes da medicina científica, apesar de o curandeirismo não ter "muita expressão como fonte de tratamento da saúde e, em geral, para qualquer outro fim” (CRUZ, s/d, p. 49).

As ideias e práticas de saúde mais urbanas, a exemplo da noção de contágio e da ingestão de medicamentos industrializados, bem como as atividades de profissionais como médicos, enfermeiros e farmacêuticos, também foram descritas por Pierson. Dificilmente eram encontrados nas comunidades mais isoladas. E quando havia, estabelecia-se um conflito entre esses profissionais de saúde e seus pacientes, especialmente quando se diagnosticava que estes haviam recorrido ao centro de saúde num estágio já avançado da doença, ou depois de se terem esgotado os recursos à medicina popular.

Costa Eduardo, em relação a Cabrobó, mostra que apesar da recorrência a práticas caseiras de tratamento, havia registros da procura por médicos e 
farmacêuticos. $\mathrm{O}$ atendimento, entretanto, não era satisfatório, aumentando a resistência da população em recorrer aos médicos para o tratamento de suas enfermidades. Vale transcrever uma das fichas com depoimento que revela a opinião de um dos informantes sobre a médica que assistia Cabrobó:

Avenor fazendo referências à doutora, disse que o povo não tem sequer um pouco de fé nas receitas e tratamentos dados por ela. Isto pelo seguinte fato: procurando certo dia João Pires, combinaram que a doutora só receitaria remédio que não tem saída na farmácia, isto para toda e qualquer doença. Assim as pessoas doentes tomando remédios não acertados e 'velhos', não podem nunca sarar. Acrescentou ainda que certo dia viajando com a doutora esta lhe disse que estava bem desgostosa com o povo de Cabrobó, pois este parecia que não lhe tinha confiança. A prova era a seguinte: quando esteve aqui pela primeira vez, em consultas fizera 30 mil cruzeiros e que este ano, ou melhor este movimento fora decaindo. Hoje faz um número reduzidíssimo de consultas. Toinho disse que quando chega um doente pobre à sua procura, ela logo pergunta se tem dinheiro. Em caso negativo dá logo uma resposta que naquele momento ela não está em serviço ou outra qualquer desculpa, não o atendendo. Não faz nenhuma caridade. ${ }^{22}$

O depoimento mostra que não só havia uma resistência da população em procurar os serviços médicos, como ela era alimentada pelo mau atendimento por parte dos médicos. Noutros depoimentos, os informantes criticam a receita de penicilina para os mais diversos casos, levando ao descrédito da medicina científica entre a população, e à perpetuação das práticas mais populares de terapia.

Levy Cruz também destaca em seu estudo o funcionamento de hospitais e postos de saúde na região de Correntina. Segundo Cruz, havia apenas um posto na cidade de Lapa, responsável pelo atendimento de toda a região leste do estado da Bahia, embora a comunidade de Correntina jamais tenha recebido qualquer assistência. O único serviço existente era o do Posto Federal de Tracoma, em que trabalhavam um médico, duas enfermeiras e uma visitadora, para identificar e tratar os casos de doenças oculares. A eficácia dos tratamentos, entretanto, era limitada, em função da paralisação do serviço de visitas domiciliares e à falta de cuidados higiênicos da população que prevenissem a contaminação pelo tracoma (CRUZ, s/d, p. 55-57).

A abordagem dos cientistas sociais que participaram do Projeto do São Francisco em relação ao tema da saúde foi feita, como vimos, mediante sua inclusão entre os aspectos que compunham a configuração sociocultural das comunidades que investigaram. A propósito, na década de 1950, já havia uma aproximação entre cientistas sociais e o tema da saúde, como nos mostra 
o trabalho do sociólogo José Arthur Rios na Divisão de Pesquisas Sociais do Serviço Especial de Saúde Pública (SESP). ${ }^{23}$ Ali, uma das preocupaçōes do sociólogo era orientar os profissionais de saúde no trato com as populações assistidas, no sentido de que não deveriam enfrentar a medicina popular de forma depreciativa. Para ele, a saúde é um elemento social, inseparável das tradiçōes culturais das comunidades rurais. E por ser mesmo um "valor social", as intervençōes educacionais e sanitárias deveriam utilizar-se, além das técnicas pedagógicas, dos métodos de ação social característicos das Ciências Sociais, com o objetivo de "vencer as resistências culturais" e concretizar a mudança social de que a otimização das condições de saúde era parte integrante (RIOS, 1953, p. 2). Os estudos no Vale do São Francisco têm a mesma perspectiva de inserção da saúde como aspecto sociocultural, o que permitiu acioná-la como chave para a compreensão do processo de mudança.

\section{Considerações finais}

O interesse pelo tema da saúde nas pesquisas do projeto do Vale do São Francisco revela o quão estava associado a processos de mudança cultural entre as populações rurais na década de 1950. Pela forma como a saúde emerge nos estudos, é possível inferir que ela constituía um aspecto que revelava informações do processo de mudança cultural caras à amplitude da investigação que se pretendia alcançar com os estudos de comunidade. Um dos aspectos destacados pelos estudos coordenados por Donald Pierson encontra-se na resistência das populações à introdução de novos elementos culturais. O conflito entre saberes, concepçôes e práticas tradicionais, de um lado, e conhecimento e intervenção com base em saberes, concepções e práticas da medicina cientifica, de outro, tornava latente que as transformações estavam acontecendo de forma profunda, atingindo diversos setores da vida da população.

A resistência das comunidades à mudança, conforme evidenciaram os estudos no Vale do São Francisco, não aponta uma incapacidade inata das populações rurais em assimilá-la. Antes, mostra a influência dos aspectos culturais na configuração da estrutura social e das condições de vida da população, como também a necessidade de adequação do processo de mudança à capacidade dessas populações em traduzi-lo culturalmente para então assimilá-lo. Pierson (1972, III, p. 465) deixa claro que o conhecimento das relaçôes sociais, em seus diversos 
contextos (cultural, geográfico, econômico, histórico), é essencial para qualquer tentativa de introdução de "mudança social dirigida". Para ele, a dificuldade de mudança estaria relacionada à força dos elementos culturais de determinada população. Como a cultura está ligada a diversas áreas da vida social, a mudança em qualquer uma delas tanto pode acarretar mudanças noutras, como sugere que as demais áreas sejam modificadas, "[...] porque a cultura de qualquer povo, num determinado momento, é um todo orgânico cujas partes são interdependentes numa unidade ativa" (ibidem, p. 472).

Os cientistas sociais envolvidos no projeto do Vale tinham a ideia de que o conhecimento científico produzido pelas Ciências Sociais deveria estar atento às diversas transformações que ocorriam nas comunidades, desde a introdução de insumos agrícolas e técnicas de irrigação, até o uso do vaso sanitário e hábitos de asseio pessoal. A esses cientistas caberia, assim, dar inteligibilidade ao processo de mudança - ser os intérpretes no estabelecimento da comunicação entre as comunidades rurais e sua estrutura sociocultural, e as instituições e agências engajadas na promoção do desenvolvimento regional (MAIO; LIMA, 2009). Assim, entender a natureza e a função da cultura, e introduzir pequenos incrementos gradualmente são, consoante Pierson, fundamentais para a eficácia de programas de mudança social. Para ele, são igualmente relevantes a colaboração do antropólogo social e do sociólogo para o trabalho do administrador, a capacitação de pessoal para o trabalho, e o equilíbrio entre as partes do programa a ser executado (PIERSON et al., 1952, p. 24).

Em O Homem no Vale do São Francisco, assim como nos outros estudos do Projeto do São Francisco, por trás da descrição detalhada da ecologia e da vida social no vale, os autores investigam a realidade social de forma que o conhecimento produzido por seu intermédio constituísse material útil para a elaboração e execução de projetos de desenvolvimento. O financiamento da pesquisa pela CVSF reforça a ideia de cooperação entre cientistas sociais e administradores e a sintonia do estudo com questôes sociais e econômicas de seu tempo.

No que tange mais especificamente à saúde, a exposição dos hábitos corporais e de higiene, das formas de tratamento popular de doenças, etc., acontece levando em consideração o alcance da penetração dos hábitos e formas de tratamento mais característicos dos centros urbanos entre a população rural. Ainda que não haja um juízo de valor explícito, há a visão de que, aos poucos, os hábitos tradicionais 
estavam sendo substituídos por outros mais "modernos", e que a execução dos programas de desenvolvimento (com obras de saneamento, irrigação, etc.) estavam acelerando este processo (PIERSON, 1972, III, p. IX).

Tomados em conjunto, nos trabalhos que compóem o Projeto do São Francisco se buscou conhecer o papel do isolamento na vida local, bem como a extensão e o caráter da mudança social que se estava introduzindo no vale. O isolamento contribuía para a manutenção das características tradicionais das comunidades, mas o aumento do contato com os centros urbanos, especialmente a partir da expansão da malha rodoviária, possibilitava a introdução de novos elementos nas mais diversas áreas da vida do homem no vale. ${ }^{24}$ Os pesquisadores destacaram que o processo de mudança tinha um caráter profundo e inexorável, em que as transformações socioeconômicas aconteciam num ritmo nem sempre acompanhado pelas populações. Daí apontarem a importância de estudos etnográficos que dessem inteligibilidade a tal processo e orientassem ações de condução da mudança, sob responsabilidade de governos e agências com programas de desenvolvimento. ${ }^{25}$

\section{Referências}

ANDRADE, R.M.T. The "Third Bank" of the Lower São Francisco River: Culture, Nature and Power in the Northeast Brazil 1853-2003. Tese (Doutorado em Filosofia) - University of California, Berkeley, 2006.

ARAÚJO, A.M. Medicina Rústica. 3. ed. São Paulo: Nacional, 1979. (Col. Brasiliana, v. 300). Populações Ribeirinhas do Baixo São Francisco. Rio de Janeiro: Ministério da Agricultura / Serviço de Informação Agrícola, 1961.

ARENSBERG, C.M.; KIMBALL, S.T. O método do estudo de comunidade. In: FERNANDES, F. (org.). Comunidade e Sociedade. São Paulo: Cia. Editora Nacional, 1973. CAMELO FILHO, J.V. A dinâmica política, econômica e social do Rio São Francisco e do seu vale. Revista do Departamento de Geografia da USP, n. 17, 2005.

A política econômica regional do Vale do São Francisco: uma busca do desenvolvimento do interior brasileiro. Revista de Estudos Sociais, ano 10, n.20, v.2, 2008.

CAMPOS, A.V. de. Políticas internacionais de saúde na era Vargas: o Serviço Especial de Saúde Pública, 1942-1960. Rio de Janeiro: Fiocruz, 2006.

CORRÊA, M. Histórias da Antropologia no Brasil: 1930-1960, testemunhos: Donald Pierson e Emilio Willems. São Paulo: Vértice, 1987. 
COSTA, E.B. Cerrado e Retiro: cidade e fazenda no Alto São Francisco. Rio de Janeiro: CVSF, 1960.

CRUZ, L. Rio Rico e os Gerais: estudo de dois grupos humanos no platô ocidental do Vale do São Francisco. Manuscrito inédito. 135 p. s/d. Arquivo Pessoal Levy Cruz.

FERRARI, A.T. Potengi: encruzilhada no vale do São Francisco. São Paulo: Sociologia, 1960.

FIGUEIREDO, R.E.D. de. Histórias de uma antropologia da "Boa Vizinhança": um estudo sobre o papel dos antropólogos nos programas interamericanos de assistência técnica e saúde no Brasil e no México (1942-1960). Tese (Doutorado) - Universidade Estadual de Campinas, Campinas, 2009.

LIMA, N.T. Public Health and Social Ideas in Modern Brazil. American Journal of Public Health, v.97, n.7, jul. 2007.

MAIO, M.C. O Projeto Unesco e a agenda das ciências sociais no Brasil dos anos 40 e 50 . Revista Brasileira de Ciências Sociais, v.14, n.41, 1999.

MAIO, M.C.; LIMA, N.T. Tradutores, intérpretes ou promotores de mudança? Cientistas sociais, educação sanitária rural e resistências culturais (1940-1960). Sociedade e Estado, Brasília, v.24, n.2, maio/agosto 2009.

McCOMB, M.R.; FOSTER, G. Kalervo Oberg, 1901-1973 (Obituary). American Anthropologist, New Series, v.76, n. 2, jun. 1974.

MICELI, S. História das Ciências Sociais no Brasil. São Paulo: Vértice, 1989.

NOGUEIRA, O. Os Estudos de Comunidades no Brasil. Revista de Antropologia, v.3, n.2, 1955.

OLIVEIRA, N. da S. Estudos de Comunidade, Ciências Sociais e Saúde: o ciclo de pesquisas no Vale do São Francisco na década de 1950. Dissertação (Mestrado em História das Ciências e da Saúde) - Casa de Oswaldo Cruz/Fiocruz, Rio de Janeiro, 2010.

PIERSON, D. Teoria e Pesquisa em Sociologia. 14a ed. São Paulo: Melhoramentos, 1970 [1945]. O Homem no Vale do São Francisco. 3 Tomos. Rio de Janeiro: Ministério do Interior / SUVALE, 1972.

PIERSON, D.; COSTA EDUARDO, O.; CRUZ, L. Hipóteses e sugestôes sobre o ensino no Vale do São Francisco. Revista Brasileira de Estudos Pedagógicos, v.XVII, n.46, abr.-jun. 1952.

RIOS, J.A. A saúde como valor social. Boletim do SESP, n. 33, abr. 1953.

SILVA, F.A. Análise comparativa de alguns aspectos da estrutura social de duas comunidades do Vale do São Francisco. 219 f. Tese (Livre-Docência) - Faculdade de Filosofia Ciências e Letras da Universidade do Paraná, Curitiba, 1955.

Xique-Xique e marrecas: duas comunidades do Médio São Francisco. Rio de Janeiro: CVSF, 1961. 
VILA NOVA, S. O singular e o universal nos estudos de comunidade. In: FALEIROS, M.I.L.; CRESPO, R.A. (Org.). Humanismo e compromisso: ensaios sobre Octávio Ianni. São Paulo: Unesp, 1996.

VILLAS BÔAS, G. A vocação das Ciências Sociais no Brasil: um estudo da sua produção em livros do acervo da Biblioteca Nacional, 1945-1966. Rio de Janeiro: Fundação Biblioteca Nacional, 2007.

\section{Notas}

${ }^{1}$ A Escola Livre de Sociologia e Política de São Paulo foi o centro pioneiro na formação profissional em Ciências Sociais no Brasil; a Smithsonian Institution, uma instituição norte-americana formada por museus e centros de pesquisa de ciências naturais, geografia e etnologia (FIGUEIREDO, 2009); e a Comissão do Vale do São Francisco, uma agência do Governo Federal brasileiro voltada para a promoção da integração e desenvolvimento socioeconômico da região do Vale do Rio São Francisco, conforme Lei Federal n 541 de 15 de dezembro de 1948.

${ }^{2}$ Programas como o de construção da hidrelétrica de Paulo Afonso, na Bahia, e de aproveitamento das águas do rio São Francisco para irrigação agrícola. Sobre tais programas, cf. Camelo Filho (2005 e 2008) e Andrade (2006).

${ }^{3}$ Os trabalhos que compõem o Projeto são: Medicina Rústica, publicado em 1959 e Populaçôes Ribeirinhas do Baixo São Francisco, publicado em 1961, ambos de Alceu Maynard Araújo; Potengi: encruzilhada no Vale do São Francisco, de Alfonso Trujillo Ferrari, publicado em 1960; Cerrado e Retiro: cidade e fazenda no Alto São Francisco, de Esdras Borges Costa, publicado em 1960; Xique-Xique e Marrecas: duas comunidades do Médio São Francisco, de Fernando Altenfelder Silva, publicado em 1961; e Análise Comparativa de Alguns Aspectos da Estrutura Social de duas Comunidades do Vale do São Francisco, apresentada por Altenfelder como tese de Livre-Docência junto à Faculdade de Filosofia, Ciências e Letras da Universidade do Paraná em 1955; o manuscrito inédito Rio Rico e os Gerais: estudo de dois grupos humanos no platô ocidental do Vale do São Francisco, de Levy Cruz; o estudo de Cabrobó, coordenado por Octavio da Costa Eduardo; e o estudo que compreende todas as regiốes separadamente estudadas pelos demais pesquisadores, O Homem no Vale do São Francisco, de Donald Pierson, que embora tenha sido concluído em 1959, foi publicado somente em 1972.

4 “A Preliminary Survey of the Valley of the São Francisco", 1949. Fundo Donald Pierson, pasta 72, AEL.

${ }^{5}$ Segundo Pierson et. al. (1952, p. 23), survey "é a investigação breve e de caráter geral que tem por objetivo reunir conhecimentos preliminares sobre os característicos de certa região, área ou instituição".

${ }^{6}$ Alceu Maynard é natural de Piracicaba, São Paulo (1913). Graduou-se em Ciências Sociais e Políticas pela ELSP (1944), onde também fez estudos pós-graduados. Chefiou uma equipe de pesquisadores no Baixo São Francisco, composta por João Vicente Cardenuto, Geraldo Semenzato e Noêmia Pereira de Toledo. À exceção de Noêmia Toledo, que era aluna da Faculdade de Filosofia, Ciências e Letras da Universidade de São Paulo, eram todos estudantes da ELSP (PIERSON, 1972, I, p. 9-11).

${ }^{7}$ Nascido em Huanuco, Peru, em 27/04/1926, Trujillo veio para o Brasil em 1951, quando se inscreveu para o curso de Pós-Graduação em Sociologia e Antropologia da ELSP. Era assistente de pesquisas de Donald Pierson quando foi encarregado de realizar a pesquisa em Potengi, também no estado de Alagoas (Ficha do curso de Bacharelado em Ciências Políticas e Sociais da ELSP. Pasta 9/3. Acervo do Centro de Documentação da Fundação Escola de Sociologia e Política de São Paulo - CEDOC/FESPSP). 
${ }^{8}$ Carta de Alfonso Trujillo Ferrari a Donald Pierson, em 04/08/1953. Fundo Donald Pierson, Pasta 66, Arquivo Edgard Leuenroth (AEL).

${ }^{9}$ Esdras Borges Costa é natural de Araraquara, São Paulo (1929). Ingressou na ELSP para o bacharelado em Ciências Sociais e Políticas em 1948. Tornou-se aluno de Donald Pierson em 1952, ao seguir na ELSP os estudos pós-graduados. A equipe de pesquisadores que coordenou no Alto São Francisco era formada por Maria Isabel dos Santos Carvalho, Gastão Thomaz de Almeida, Neide Carvalho e Aldemar Moreira (alunos da ELSP) (PIERSON, 1972, I, p. 11-12).

${ }^{10}$ Relatório de viagem de Maria Isabel dos Santos Carvalho, s/d. Fundo Donald Pierson, Pasta 64, AEL.

${ }^{11}$ Fernando Altenfelder é natural de São Paulo (1916). Ingressou na ELSP em 1943, tendo sido posteriormente admitido como professor-assistente (Antropologia) em 1947, enquanto fazia o mestrado na mesma instituição. A equipe orientada por Altenfelder era composta por sua esposa Lydia Del Pichia Altenfelder Silva e Maria Galvão Cardoso, da Divisão de Estatística e Documentação Social do Departamento de Cultura da Prefeitura de São Paulo, e Cândido Procópio Ferreira de Carvalho, aluno da ELSP (CEDOC/FESPSP; Carta de Donald Pierson a Fernando Altenfelder em 05.04.1952. Fundo Donald Pierson, Pasta 65, AEL).

${ }^{12}$ Levy Porfírio da Cruz é natural de Recife, Pernambuco (1924). Formado em Engenharia Agronômica pela Escola Superior de Agricultura de Pernambuco (1947), ingressou no curso de pós-graduação da ELSP em 1948. Foi assistente de pesquisa de Donald Pierson e lecionava Ecologia Humana na ELSP quando foi convidado a participar do Projeto do São Francisco. Cruz chefiou a equipe formada por Aparecida Joly Gouveia (aluna pós-graduada da Escola e funcionária do Ministério da Agricultura), Frederico de Barros Brotero (aluno da ELSP) e Gastão Thomaz de Almeida (funcionário da Secretaria de Agricultura do Estado de São Paulo), que passou seis meses na região (início de 1952) - (Entrevista concedida por Levy Cruz a Marcos Chor Maio em 19/09/2007).

${ }^{13}$ Ibidem.

${ }^{14}$ Octavio da Costa Eduardo é natural de Bebedouro, São Paulo (1919). Ingressou na ELSP em 1938, onde mais tarde passou a lecionar Antropologia. A equipe chefiada por Octavio da Costa Eduardo era composta por Artur de Morais César, Plínio Figueiredo e Natália Rodrigues Bittencourt, alunos do curso de Antropologia ministrado por Eduardo na ELSP, e também Paulo Piazza (Entrevista concedida por Octavio Eduardo a Marcos Chor Maio e Nemuel Oliveira em 26/11/2009).

${ }^{15}$ A pesquisa em Cabrobó foi realizada em dois períodos: o primeiro entre 1952 e 1953, o segundo em 1960 (ibidem).

${ }^{16}$ Fichas de trabalho de campo, gentilmente disponibilizadas por Octavio Eduardo em 26/11/2009.

${ }^{17}$ Donald Pierson nasceu em Indianapolis (EUA), em 1900. Graduou-se (1927) no College of Emporia, com especialização em Psicologia, História e Literatura. Em 1933, já na University of Chicago, tornou-se Master of Arts, e em 1939, Ph.D. em Filosofia, com especialização em Sociologia e Antropologia Social. Trabalhou na Universidade de Fisk entre 1937 e 1939, e foi, naquele último ano, convidado pela direção da ELSP a ocupar as cátedras de Sociologia e Antropologia Social. Ali criou e dirigiu o Departamento de Sociologia e Antropologia, em 1940, ampliado no ano seguinte para a Divisão de Estudos Pós-Graduados,onde permaneceu até 1959. Outras informações sobre Pierson, cf.: Correa (1987).

${ }^{18}$ Carta de Donald Pierson a Alceu Maynard Araújo em 15/07/1959. Fundo Donald Pierson, Pasta 66. AEL.

${ }^{19}$ Segundo o autor, a palavra "rústica" é utilizada no sentido de relativo ao meio rural. 
${ }^{20} \mathrm{O}$ uso da expressão "medicina de folk", ou "mundo do folk" (PIERSON, 1972) mostra a influência de Robert Redfield nos trabalhos que compõem o Projeto do São Francisco. A própria característica empírica e a abordagem comparativa reforçam sua proximidade à perspectiva vigente no trabalho de Redfield, especialmente Civilização e Cultura de folk (1949) - investigação da estrutura sociocultural mediante o contraste entre comunidades contemporâneas que apresentavam características progressivamente afetadas por influências externas. Sendo a variação cultural considerada dependente do grau de isolamento da comunidade em relação aos centros urbanos, o foco da investigação recaía sobre o entendimento do processo de mudança, eixo que perpassa todos os trabalhos do Projeto do São Francisco.

${ }^{21}$ Pierson afirma que algumas localidades estudadas, por iniciativa própria e com ajuda da Comissão do Vale do São Francisco, instalaram sistema de abastecimento de água (PIERSON, 1972, II, p. 170). 22 Ficha de 20/01/1953. "Informante Avenor - Dra. Isaura - opiniōes sobre a médica Cabrobó". Arquivo Pessoal Octavio da Costa Eduardo.

${ }^{23} \mathrm{O}$ Instituto de Assuntos Interamericanos (IAIA), órgão do Departamento de Estado norte-americano, criou um programa de saúde e saneamento voltado para a América Latina. O Serviço Especial de Saúde Pública (SESP) advém deste programa, nascendo principalmente em função da Segunda Guerra Mundial, já que ela impunha a necessidade de matérias-primas essenciais para a indústria bélica dos Estados Unidos (o combate à malária e outras doenças levaria ao aumento da produção destas matérias-primas pelos trabalhadores brasileiros) e de otimização das condições de salubridade das bases do norte e nordeste brasileiros, onde estavam soldados americanos (CAMPOS, 2006).

${ }^{24}$ Mudanças como a construção de infraestrutura visando ao combate às dificuldades causadas pelas secas, uso de técnicas de irrigação, facilidade de acesso a meios de comunicação como rádio e jornais, entre outros elementos que afetavam diretamente a vida das populações do Vale.

${ }^{25}$ N.S. Oliveira participou da redação do artigo, da coleta e análise dos dados. M.C. Maio participou da redação do artigo e da análise dos dados. 
Social Sciences and health in the research cycle of São Francisco Valley (1950-1960)

Between 1940 and 1960, there was extensive academic research in the field of sociology and anthropology of so-called community studies in Brazil. In the era of large projects in the social sciences in the 1950 s, involving research on race relations, education and health, we highlight the research conducted in the São Francisco Valley, under the coordination of the sociologist Donald Pierson. Attention is given in this paper to the issue of health in these studies as a means to make intelligible the relevant issues at the time, namely: cultural resistance to change, relations between tradition and modernity, tensions and complementarities between scientific knowledge and folk healing practices, among others. The examination of the research project of San Francisco identified the issue of health, linked to socioeconomic and cultural aspects, emerges as a key to the knowledge of living conditions and social reality of the communities investigated. Social scientists have sought to describe them in detail and comprehensively, taking the process of cultural change as the main axis of research. This paper presents the research that formed the said project and shows how social scientists have addressed the issue of health in their work. Linked by the theme of health, social sciences and the development context of the 1950s are gathered in the San Francisco Project, whose research allows us to understand the dynamics of social change in that period.

> Key words: Social Sciences; Health History; Community Studies; São Francisco Valley. 